\title{
A utopia concreta da poesia: "Uma árvore de veneno" de Blake
}

John Brenkman

Resumo: O ensaio examina algumas perspectivas amplas sobre a arte que vêm da tradição do "marxismo crítico", por meio da análise de um poema de Canções da experiência, de William Blake. A leitura deve tanto à hermenêutica e ao pós-estruturalismo quanto aos escritos estéticos da Escola de Frankfurt. Palavras-chave: William Blake, marxismo, hermenêutica, pós-estruturalismo.

Abstract: The essay examines some broad perspectives on the art that comes from the tradition of "critical Marxism", by analyzing a poem of Songs of Experience, written by William Blake. The reading is related to hermeneutics and post-structuralism, as the aesthetic writings of the Frankfurt School. Keywords: William Blake, Marxism, hermeneutics, post-structuralism. 


\section{Considerações preliminares ${ }^{1}$}

Raramente a discussão sobre lírica e sociedade vai além das considerações "extratextuais" que envolvem, basicamente, o papel das ideias sociais e políticas no desenvolvimento biográfico e intelectual de um poeta ou no conteúdo temático da poesia. ${ }^{2}$ A crítica marxista espelha essa deficiência ao relegar a poesia às margens de suas investigações da experiência social e estética. A poesia de William Blake nos encoraja a contrariar igualmente os hábitos da crítica marxista e não marxista, reconhecendo que a sociedade e a política moldam o próprio projeto de trabalho de um poeta e a dinâmica interna da linguagem poética, seus processos de figuração, seu status como ato linguístico, suas formas e técnicas, e seus efeitos no processo de leitura.

Blake foi um poeta das instáveis décadas do final do século XVIII e início do XIX, escrevendo no exato momento em que as revoluções democráticas estavam se institucionalizando como regime de classe da burguesia. As reivindicações de liberdade e liberação que impulsionaram poetas e romancistas nesse período estavam rapidamente se defrontando com a necessidade de estabelecer a nova ordem econômica do capitalismo. A contribuição vital de Blake para nossa herança cultural reside na resposta que sua poesia deu a essa mudança na relação da arte com a evolução da sociedade burguesa. Ele foi um poeta que constantemente refletiu sobre as possibilidades políticas e históricas da imaginação. Para Blake, a poesia é a imposição ativa da imaginação ou da fantasia nas lutas contra os valores e instituições dominantes. Lançando o poeta no duplo papel de visionário e de voz da condenação, ele atribuiu um poder de utopia e negação à linguagem poética.

É essa interação entre utopia e negação, imaginação e crítica que torna a poesia de Blake pertinente para as teorias sociais e estéticas de pensadores como Ernst Bloch e Herbert Marcuse, Walter Benjamin e T. W. Adorno. Neste ensaio, examinarei algumas perspectivas amplas sobre a arte que vêm dessa tradição do "marxismo crítico", por meio da análise de um poema de Canções da experiência. A leitura deve tanto à hermenêutica e ao pós-estruturalismo quanto aos escritos estéticos da Escola de Frankfurt. ${ }^{3}$ publicado pela Cornell UP (J. B.).

3 As figuras associadas à Escola de Frankfurt produziram, de fato, a mais importante crítica de poesia que existe na tradição marxista. Ver, especialmente, Walter Benjamin, Charles Baudelaire: A lyric poet in the era of high capitalism. Trad. Harry Zohn (Londres, 1973); e Theodor W. Adorno, "Lyric poetry and society", Telos, 20 (Summer 1974), p. 56-71. 
De Bloch, tomei a expressão "utopia concreta". Com ela, Bloch quis dizer que as possibilidades utópicas estão latentes na liberdade e na auto-organização que os grupos e classes sociais possuem, intermitente e fragmentariamente, em sua existência cotidiana, experiências políticas, mitos e empenho artístico. ${ }^{4}$ Essas tendências latentes têm como herança todos os esforços inacabados ou abortados, na história, para propagar justiça e felicidade. A herança da utopia é, portanto, uma história descontínua que precisa ser construída a partir das tradições culturais e das lutas e revoltas populares do passado. A questão que nós podemos extrair das reflexões de Bloch é esta: de que modo a poesia é portadora da esperança utópica, dessa latência histórica que está ao mesmo tempo dentro e além da sociedade?

De Marcuse, tomarei emprestada a tese sobre arte e literatura desenvolvida em seu último trabalho publicado - A dimensão estética: "A lógica interna da obra de arte acaba no surgimento de uma outra razão, uma outra sensibilidade, que desafia a racionalidade e a sensibilidade incorporadas nas instituições sociais dominantes". A expressão "acaba no surgimento de" sugere, em primeiro lugar, que a arte é utópica na medida em que antecipa novas ordens de razão e de sensibilidade, que só podem ser garantidas pela ação política e pela transformação social, e, em segundo lugar, que a antecipação utópica é, todavia, concreta na medida em que se origina do que é realizado esteticamente na obra de arte. A tese de Marcuse leva a uma segunda questão sobre lírica e sociedade: como a "lógica interna" do poema manifesta, ao mesmo tempo, uma lógica contrária às interações restritivas organizadas pela sociedade? Enquanto Bloch e Marcuse ajudam a estabelecer as finalidades da interpretação e a figurar as questões que um estudo sociologicamente crítico da poesia precisa tratar, as próprias reflexões estéticas deles apoiam-se em suposições abertas à contestação proveniente de muitas direções na teoria recente da interpretação e da arte. Bloch sustenta que as grandes obras artísticas são, em parte, ideologia, em parte utopia autêntica. A primeira tarefa da análise é dissolver a carapaça ideológica da obra, expondo os modos pelos quais ela serve a interesses mais particulares do que gerais e legitima as formas de dominação que prevalecem em sua própria sociedade; uma vez que essa carapaça ideológica é dissolvida, o âmago utópico da obra poderia, supostamente, resplandecer; um núcleo radiante de significados e imagens que expressam as lutas e esperanças da

Ver BLOCH, Ernst."Karl Marx and humanity: the material of hope" e "Upright Carriage, Concrete Utopia". In: On Karl Marx (Nova York, 1971), p. 16-45 e 159-73, respectivamente.

5 Ver MARCUSE, Herbert. The aesthetic dimension: toward a critique of marxist aesthetics (Boston, 1978), p. 7. (A dimensão estética. Trad. Maria Elisabete Costa. São Paulo: Martins Fontes, 1986.)

246 • BRENKMAN, John. A utopia concreta da poesia: “Uma árvore de veneno" 
humanidade. A concepção de interpretação de Bloch partilha, com a hermenêutica de Heidegger e de Gadamer, a compreensão de que os significados culturais só emergem das obras historicamente situadas e são apropriados apenas em contextos historicamente situados, mas ele tende a ver os significados válidos da cultura como um repositório semântico que se preserva intacto através de períodos e épocas históricas. Daí a noção questionável de que a interpretação pode, com segurança, separar o aspecto válido e verdadeiro de uma obra de seu aspecto ideológico e falso. A crítica contemporânea, na esteira de Heidegger e, mais recentemente, do pós-estruturalismo e da desconstrução, levanta um problema inescapável referente à nossa própria recepção da arte e da literatura do passado, a saber: não há, na verdade, base de significado ou posição segura sobre a qual possamos, com certeza, extrair as significações válidas de uma obra.

As reflexões estéticas de Marcuse acentuam a unidade da forma. Em toda a sua obra, ele transcreve, em termos socialmente críticos, a experiência estética que foi a base da estética burguesa desde Schiller. Marcuse atribui o poder utópico e negativo da arte ao nítido contraste que os indivíduos experimentam entre a unidade ou harmonia que eles apreendem na obra de arte e a desarmonia e conflito que caracterizam as relações sociais que eles encontram na vida cotidiana. A noção de harmonia formal do trabalho artístico tem sido contestada por uma série de teorias contemporâneas da dinâmica formal e significante dos textos literários. A transação entre escrita e leitura, entre o texto poético e sua recepção, creio eu, não pode mais ser frutiferamente descrita como a apropriação interior pelo sujeito de uma harmonia exteriormente percebida de elementos sensoriais e simbólicos.

Sem o compromisso de resolver o problema que a hermenêutica e o pós-estruturalismo colocam para o pensamento estético do marxismo crítico, esbocei os problemas relevantes para esclarecer os pressupostos de minha leitura de Blake. Pois o meu interesse é transpor o problema da relação entre lírica e sociedade e do poder utópico-negativo da poesia para a questão da linguagem poética, da poesia como uma prática de linguagem e da interação de escrita e leitura.

A leitura que apresentarei de "Uma árvore de veneno" é orientada por três conjuntos de proposições destinadas a estimular esse diálogo entre a teoria social crítica e a teoria literária contemporânea:

(1) A dialética social da arte não vem do conflito entre uma realidade dividida e uma obra unificada, mas toma antes a forma de um conflito no interior da obra. Por isso, a contralógica social que o poema manifesta resulta da contradição interna do poema como texto, não da totalidade do poema como bela aparência. A literatura é uma prática 
que age sobre a linguagem. O texto entra em uma complexa, mas determinada, relação com o mundo social, porque a linguagem é o verdadeiro fundamento da interação social. O poder utópico da poesia se origina de suas conexões concretas, como uma prática de linguagem, com a realidade social e política do momento, mais do que de qualquer capacidade para refletir essas conexões ou se pôr acima delas.

(2) A linguagem poética solicita, incita, exige uma leitura, uma leitura que, ao mesmo tempo, permite que os efeitos de condensação poética irrompam no poema e que vincule esses efeitos à situação ou ato da própria escrita. Ler implica sempre esse duplo movimento receptividade para com a linguagem, que é polivalente e sobredeterminada, e momentos de decisão em que a polivalência e a sobredeterminação são relacionadas novamente ao lugar ou situação de que o poema se originou. Minha perspectiva, aqui, será a de que esse lugar da gênese do poema é social. Pode-se fazer uma analogia entre a leitura de poesia e a interpretação psicanalítica. O analista escuta com o que Freud denominou de "atenção suspensa" ou "flutuante", a fim de ouvir o que reverbera no discurso do sujeito e em seus silêncios; do outro lado do diálogo, o sujeito é premido para o que Lacan chamou de "momento de concluir", em que ele ou ela sente a pressão do inconsciente e o integra em seu discurso real com o analista, permitindo que o inconsciente interrompa as falsas "conclusões" que até então tinham resistido a ele. Os dois lados da leitura de poesia são uma dialética dessa ordem, entre a atenção flutuante e o momento de concluir. O leitor, entretanto, se assemelha mais ao paciente do que ao analista, na medida em que as interpretações, geralmente em nome de sua própria coerência, tendem a resistir aos efeitos do texto poético. Isto não implica argumentar a favor do adiamento indefinido das decisões interpretativas. Essas decisões sempre ocorrem, mesmo quando são dissimuladas, como na retórica da crítica desconstrutivista. Todo momento de concluir interpretativo liga a interpretação e o texto como os dois lugares histórica e socialmente situados de experiência estética.

(3) A transação entre escrita e leitura é, assim, o embate entre a situação social de produção e a de recepção literárias. O problema da ideologia é mais bem focalizado nesse embate e nessa transação. A arte e a literatura se tornam enredadas nas lutas ideológicas vitais do presente por meio do conflito de interpretações, dos esforços em disputa para entender os textos da herança cultural, concreta e reflexivamente. A experiência estética não é dada, mas formada no jogo entre escrita e leitura. A herança cultural não é dada, mas construída. Essa herança se torna investida de significado para o presente por meio do conflito de interpretações. 


\section{“Uma árvore de veneno"}

Primeiramente, vamos reproduzir o poema na íntegra:

A Poison Tree
I was angry with my friend:
I told my wrath, my wrath did end.
I was angry with my foe:
I told it not, my wrath did grow.
And I water'd it in fears,
Night \& morning with my tears;
And I sunned it with smiles,
And with soft deceitful wiles.
And I grew both day and night,
Till it bore an apple bright.
And my foe beheld it shine,
And he knew that it was mine.
And into my garden stole,
When the night had veild the pole;
In the morning glad I seel
My foe outstretch'd beneath the tree.

Uma árvore de veneno
Zanguei-me com meu amigo:
A ira cessou, eu a digo.
Com o inimigo zanguei-me:
A ira cresceu, eu calei-me.
E a reguei de alma sombria
Com meu pranto noite e dia;
E a expus ao sol de gentis
Risos e falsos ardis.
E cresceu noite e manhã,
Dando luzente maçã;
Ao ver o brilho que tinha,
E sabendo que era minha,
Veio o inimigo ao pomar
Após a noite tombar.
Bem cedo o vi, com agrado,
Ao pé da árvore estirado.*

\begin{tabular}{|l|} 
Uma árvore venenosa \\
Falei, meu ódio do meu amigo: \\
Tive ódio de um inimigo: \\
não disse, o ódio aumentou. \\
Dia e noite, com temor, \\
Eu, com meu pranto, reguei-o; \\
Ao doce riso, ao calor \\
De gentis ardis, deixei-o. \\
E crescendo, noite e dia, \\
Maçã brilhante medrou. \\
O inimigo a cobiçou, \\
Mas só a mim pertencia. \\
A furto, invadiu meu horto \\
Quando ainda escurecia. \\
De manhã, eu, co' alegria, \\
Junto à árvore, o vi morto.
\end{tabular}

Depende-se muito aqui da relação da primeira estrofe com o restante do poema, à medida que ele expõe o que aconteceu à ira que não foi comunicada ao inimigo. Toda vez que alguém lê o poema, creio eu, a primeira estrofe tem a força de uma afirmação moral. O tempo passado estabelece a dupla perspectiva da ação de Blake naquele tempo e de seu julgamento agora. O perigo ou a infelicidade de uma ira que cresce, em

* Esta tradução é de Paulo Vizioli, in BLAKE, William. Poesia e prosa selecionadas. São Paulo: Nova Alexandria, 1993, p. 68-9. Apresentamos uma tradução alternativa que, apesar de não respeitar o esquema rímico do original, preserva certa imagem central para a análise de Brenkman, que foi alterada na tradução de Vizioli. É o caso de "fears", traduzido por "alma sombria", no início da segunda estrofe. (Nota dos tradutores). 
comparação com uma ira que acaba, estabelece uma série de valores ou preferências que é quase evidente. E tudo isso é confirmado no relato da angústia resultante que ele experimentou e do dano que ele causou ao seu inimigo. Lê-se o poema como uma espécie de confissão em que o Blake que fala partilha com o leitor um julgamento reflexivo sobre as ações de Blake no passado, ancorado na visão de que falar sobre o ódio é saudável e de que não falar sobre ele é prejudicial, até mesmo autodestrutivo.

Num outro extremo, entretanto, emerge uma leitura que contraria essa em todos os seus detalhes. Os dois últimos versos do poema, rompendo o consistente tempo passado do restante, podem ser tomados pelo seu valor de face: "Na manhã alegre, eu vejo/ Meu inimigo estirado debaixo da árvore”. É uma alegria transcendente! Ele obteve sua satisfação e sua ira finalmente se expressou, produzindo o prazer absoluto de ver seu inimigo destruído. Alguém poderia tentar evitar essa leitura argumentando que a expressão "alegre eu vejo" não está realmente no tempo presente, mas é antes uma construção elíptica, algo como "feliz fiquei de ver". Mas a leitura amoral do poema se baseia em outros aspectos de sua estrutura total. Em primeiro lugar, há duas oposições na primeira estrofe, não só entre comunicar ou não a ira, mas também a diferença entre amigo e inimigo, sugerindo que não há meios não destrutivos de exprimir o ódio ao inimigo, mas que ele precisa ser representado. Em segundo lugar, as palavras e a sintaxe do poema não são particularmente investidas de conotações afetivas; o tom é uniforme e essa segunda leitura o mantém assim, ao construir a primeira estrofe não como uma afirmação moral, mas como uma declaração de fato: o ódio pode ser expresso e imediatamente dissipado em relação a um amigo, mas não em relação a um inimigo. De fato, pode-se levar esta leitura à sua conclusão lógica e dizer que o poema como um todo, longe de ser uma confissão, se parece mais com uma série de instruções sobre como trapacear um inimigo e sentir alívio, até mesmo regozijo.

Cada uma dessas leituras pode responder por si mesma, colocando no mesmo patamar os vários detalhes do poema. Nesse sentido, o poema gera ambas as leituras. No entanto, nenhuma leitura pode responder pela possibilidade da outra, exceto para declarar que ela é produto de uma interpretação errônea; elas só podem acusar-se entre si de moralismo ingênuo e amoralidade, respectivamente. Por outro lado, tampouco é adequado se contentar com esses resultados e declarar a indecisão formal ou lógica do poema, uma pura oscilação entre dois significados mutuamente excludentes. Pois essa indecisão também representa duas situações contrárias de experiência, remorso e não remorso, condenação e frieza, constituindo um impasse ético que a leitura do poema não precisa ainda aceitar, isto é, decidir afirmar. 
A própria uniformidade de tom do poema permite a cada leitura investi-lo com os afetos apropriados a ela. Na primeira leitura, o poema adquire o solene espanto de testemunhar uma ação que o próprio falante tem dificuldade de acreditar que cometeu. A segunda leitura, por outro lado, aceita o valor em face do júbilo final do falante e, por sua vez, investe a superfície atonal do poema com a conotação de frieza. $\mathrm{O}$ tom se torna sintoma de um regozijo derivado de uma emoção totalmente diferente, isto é, a ira que teve de seguir seu caminho por elaborados desvios a fim de se manifestar no logro fatal do inimigo. O conceito [conceit ${ }^{6}$ que dá ao poema seu título é a imagem dessa transformação tortuosa da cólera em temor, em má-fé e, finalmente, em logro:

E a reguei de alma sombria

Com meu pranto noite e dia;

$\mathrm{E}$ a expus ao sol de gentis

Risos e falsos ardis.

E cresceu noite e manhã,

Dando luzente maçã.

Sem fazer referência a um julgamento moral contra a má-fé e o logro, descobrimos, na imagem de regar a ira (árvore) e expô-la ao sol, uma cisão presente no sujeito entre seu sentimento interior (medo) e as demonstrações exteriores de fraternidade (gentis risos, falsos ardis) que, a partir daquele momento, impede qualquer relação direta entre emoção e ação. Essa distorção da experiência não está sujeita a uma condenação moral, no sentido de um julgamento contra o próprio falante, pois ele não fez uma escolha que pudesse ser julgada. Ele sofreu os efeitos de uma cólera que não pode imediatamente se expressar e se resolver.

$\mathbf{O}$ conceito [concept] da árvore de veneno, ${ }^{7}$ estendendo sua simplicidade e completude ao longo das últimas três estrofes como um todo, não obstante, tem em seu

Diferentemente de concept, o termo conceit, embora traduzido por conceito, deve ser tomado no sentido de agudeza, como bem observou João Adolfo Hansen, a quem registramos nosso agradecimento. (Nota dos tradutores).

Se se fosse buscar o significado da imagem em sua fonte bíblica para suprir o que está faltando no conceito [concept], o poema poderia ser concebido como sátira do mito edênico. Deus se tornaria o falante, e a espécie humana, o inimigo seduzido pela tentação de algo invejável. 
centro um elemento indeterminado - a "maçã brilhante". Todos os outros elementos isolados da imagem que equiparam a cólera não declarada a uma árvore facilmente encontram seus equivalentes apropriados. Dentro da lógica do conceito [concept], a imagem da maçã é apenas vagamente motivada, como pela ideia de que ela é o "fruto" da ira. O significado de "maçã brilhante" é, de outra maneira, não passível de especificação do ponto de vista do próprio conceito [concept]. Ela poderia ser qualquer coisa - um objeto, uma situação, uma pessoa -, contanto que preenchesse uma condição geral: a de que fosse, aos olhos do inimigo, um bem invejável do falante. Aqui, a indeterminação é um exemplo extremo de condensação metafórica. Mil e uma narrativas poderiam ser contadas que girassem em torno de um episódio em que o inimigo de um personagem, pensando que está prestes a despojar o protagonista de um bem valioso, cava sua própria ruína:

Ao ver o brilho que tinha,

E sabendo que era minha,

Veio o inimigo ao pomar

Após a noite tombar.

Essas linhas resistem a uma leitura moral do poema mais do que qualquer outro trecho, pois mostram que se poderia contar com esse inimigo para tentar roubar o sujeito de seu bem. Blake havia calculado exatamente quais seriam as ações e reações de seu inimigo, tendo imputado ao outro o mesmo antagonismo destrutivo que havia descoberto dentro de si mesmo. Essa igualdade entre protagonista e antagonista leva a leitura moral a perder sua força. A aparente diferença entre protagonista e antagonista foi dissolvida em uma identidade essencial entre um e outro. A essa altura, a indeterminação da maçã e a natureza prototípica da narrativa produzem uma significação que excede a compreensão tanto da leitura moral quanto da amoral. A história do poema é abstrata, mas não no sentido de que ela é uma abstração. Ao contrário, revela a forma de abstração que é historicamente específica da sociedade capitalista. A narrativa prototípica e a imagem da "maçã brilhante" são como um vórtice que traga tudo para dentro de si mesmo. Qualquer coisa poderia ser o bem invejável em torno do qual gira a luta de morte entre Blake e o inimigo. A possessão não é meramente um elemento do antagonismo entre eles, mas sua causa; a possessão pré-forma, socialmente, a relação entre um e outro como uma relação de igualdade e inveja, sendo seu espelhamento mútuo tão completo que o protagonista 
precisa apenas imputar, de forma calculada, seus próprios objetivos e motivos ao outro a fim de tornar seu esquema um sucesso. As condições da imagem-narrativa central, em outras palavras, são, de fato, preenchidas apenas nas condições sociais do capitalismo, em que o individualismo possessivo não é senão a manifestação ideológica e caracterológica de uma prática de troca em que tudo, ou seja, qualquer objeto, situação ou pessoa é passível de uma designação econômica de valor que é, então, a mesma para todos os indivíduos, e se torna algo a ser possuído. É somente nessas condições que a igualdade dos indivíduos necessariamente toma a forma de antagonismo entre indivíduos. A inveja, um termo tomado de empréstimo à ética das sociedades pré-capitalistas, é antes um nome para a lei fundamental de interações na sociedade capitalista como um todo.

O poder extraordinário deste poema simples deriva do jogo da imagem da "maçã brilhante" que é, ao mesmo tempo, a mais abstratamente indeterminada e a mais concreta imagem socialmente determinada do poema. O movimento expresso da imagem possui três momentos distintos. No primeiro, como um elemento do conceito [concept], a "maçã brilhante" representa o efeito do ódio não expresso, um resultado a que se chegou no curso dos eventos narrados. No segundo, e ao contrário do anterior, como uma metáfora do processo social de abstração que constitui a inter-relação e interação de indivíduos, a "maçã brilhante" representa a causa do antagonismo da qual se originou a narrativa. O conceito [concept] substitui o efeito pela causa. A "maçã brilhante" é, então, no terceiro momento de sua figuração, o tropo denominado metalepse. A metalepse toma a forma aqui de uma contradição entre o que é narrado e a própria narrativa, pois descobrimos a causa social da narrativa do poema na imagem que, inicialmente, representou o efeito psicológico do que foi narrado, isto é, a ira não expressa do falante. Para acompanharmos essa guinada figurativa na linguagem do poema, operamos uma ruptura entre as duas leituras, a moral e a amoral, que o texto engendrou.

Em “Uma árvore de veneno", a crítica da sociedade burguesa é expressa não tematicamente, mas na própria articulação do texto e na dinâmica que ela provoca. A teoria linguística estabeleceu a distinção entre o énoncé (enunciado) do texto e a énonciation (enunciação), ou seja, entre o que é dito e o ato de dizê-lo. Em nosso contexto, a terminologia original de Roman Jakobson basta, distinguindo o evento narrado e o evento de fala. No nível do evento narrado de "A árvore de veneno", uma ira não expressa resulta na destruição de um antagonista seduzindo-o por meio de um bem invejável. O evento de fala do poema, insisto, deveria ser compreendido em termos sociais e, mesmo, políticos. O texto gerou duas leituras conflitantes e irreconciliáveis, cada qual apreendendo o status do poema como evento de fala de um modo 
específico: como uma confissão ou julgamento moral, de um lado, e como apresentação fria do fato ou cenário para uma ação destrutiva, de outro. Nenhuma dessas leituras pode ser o verdadeiro entendimento do texto, pois nenhuma pode explicar ou cancelar a outra. Nossa interpretação foi forçada a ir além da leitura moral e da amoral. O poema deve antes ser interpretado em termos da produção dessas duas leituras parciais e cegas. Ele gera essas leituras porque elas correspondem aos dois polos da consciência ética por meio dos quais os indivíduos realmente vivenciam as relações sociais do mundo capitalista. A leitura moral corresponde a uma falsa moralidade de boa vontade e honestidade - que teria sido, a propósito, o alvo simples de uma sátira, se Blake tivesse conservado o título do poema tal como ele aparece no caderno de notas de poema: “Tolerância cristã"! A leitura amoral, por outro lado, corresponde àquela forma de individualismo em que os homens, tendo-se tornado intercambiáveis, são privados da própria individualidade em nome da qual agem.

A dialética do texto consiste em impor as leituras moral e amoral, que representam os dois polos da experiência ética na sociedade burguesa, e, então, forçar essas duas leituras de volta à figura da "maçã brilhante", para que o leitor entenda o poema. Ambas as leituras estão condenadas ao fracasso, já que tomam a "maçã brilhante" antes como o efeito da ira do que como a causa social do antagonismo entre os indivíduos. A metalepse, ao depreender nossa interpretação das duas leituras, dá forma - ou figura - à diferença entre esse ato de fala poética e a ética vivida na sociedade burguesa.

Permitam-me explicar essa formulação sobre a forma poética, contrastando os resultados da análise com a posição que Marcuse defende. Para ele, a experiência estética marca a diferença entre o real e o possível, apresentando uma imagem ou aparência cuja completude a separa das condições existentes e das experiências prevalecentes da vida social. A arte é sublimação no sentido de que ela transforma o real em bela aparência; acompanhar essa sublimação estética, argumenta Marcuse, é um processo de dessublimação que ocorre na percepção estética:

A transcendência da realidade imediata despedaça a objetividade reificada das relações sociais estabelecidas e abre uma nova dimensão da experiência: o renascimento da subjetividade rebelde. Assim, com base na sublimação estética, tem lugar uma dessublimação na percepção dos indivíduos - em seus sentimentos, juízos, pensamentos; uma invalidação das normas, necessidades e valores dominantes. ${ }^{8}$ 
Ora, "Uma árvore de veneno", de Blake, de fato invalida as formas dominantes da experiência e da consciência ética, as que estão incrustadas nas práticas e interações socialmente organizadas da sociedade burguesa. O poema realiza isso não por meio da bela aparência do todo estético, mas pela contradição presente no texto entre as leituras que ele gera e a gênese dessas leituras. As "normas, necessidades e valores dominantes" que o poema nega são tão essenciais às operações internas do texto, quanto inerentes à vida social. O que é sentido, pensado e julgado dentro das formas históricas da consciência ética que o sujeito burguês precisa viver é parte da dimensão estética do poema, aqui como a dinâmica das leituras que corresponde à polaridade em tal consciência ética. Não é a unidade, mas a divisão ativa do texto que invalida essas formas socioéticas.

Da mesma forma, o poder utópico do poema reside não na sua proteção de uma aparência estética de inteireza, mas em seu ato concreto de fala. A concretude da utopia, entretanto, não consiste, como concebia Bloch, no repertório de imagens de felicidade e liberdade. O utópico está mais completamente vinculado ao negativo. $O$ poema anuncia a necessidade de uma consciência ética que não pode ainda ser vivida e representada, mas o faz na fratura entre énoncé e énonciation. A dimensão utópica do poema é encenada em uma fala poética que manifesta a luta entre as condições sociais da fala do poeta e as possibilidades latentes de fala. O movimento de figuração, por meio dos três momentos do tropo da "maçã brilhante", invalida as duas leituras capazes de dar ao evento narrado (énoncé) e ao conceito (árvore $=$ ira) consistência e, dessa maneira, nega aquelas formas de experiência ética que podem ser vividas no contexto social do poema. O que o poema diz é negado no seu ato de dizê-lo. O que chamei de forma ou figura poética é aqui apenas essa diferença entre énoncé e énonciation, uma encenação da divergência entre o real e o possível, o vivido e o utópico. "Uma árvore de veneno" aponta para um futuro em que sua própria história e seu modo de narrá-la não seriam mais necessários.

A lógica interna da escrita de Blake não é a de um monumento cultural separado do tempo e da mudança. Justamente por isso, uma leitura historicista de Blake, que visasse apenas a "situá-lo" em "seu próprio tempo", esqueceria que o futuro é uma dimensão indispensável do diálogo poético de Blake com o tempo e a história. A construção socialmente crítica da herança cultural evita tanto a ideia de que a arte está acima da história, quanto a de que a arte está simplesmente limitada a seu próprio tempo. Quando Marx contrastou as revoluções burguesas do século XVIII com as proletárias do XIX, ele viu, em cada qual, uma desarmonia específica de forma e conteúdo: 
A revolução social do século XIX não pode tirar sua poesia do passado, e sim do futuro. Não pode iniciar sua tarefa enquanto não se despojar de toda veneração supersticiosa do passado. As revoluções anteriores tiveram que lançar mão de recordações da história antiga para se iludirem quanto ao próprio conteúdo. A fim de alcançar seu próprio conteúdo, a revolução do século XIX deve deixar que os mortos enterrem seus mortos. Antes a frase ia além do conteúdo; agora é o conteúdo que vai além da frase. ${ }^{9}$

Blake se situa entre as realidades das revoluções burguesas e as possibilidades da revolução socialista. Historicamente, ele é um poeta das Revoluções Francesa e Americana. Diferentemente das revoluções que mexeram com sua imaginação, sua prática poética não para abruptamente, enrijecendo as formas de liberdade e destruindo os conteúdos de liberdade. Blake não era de seu tempo. Sua poesia reivindicava um futuro a que as revoluções burguesas tiveram de resistir. Concluo com essa justaposição de Blake e Marx, de política da poesia e de poética da história, não para colocar Blake dentro do quadro de referência de Marx, mas para situar Marx dentro de um processo político e cultural que inclui, como um momento produtivo e profético, a poesia de Blake. Isso se torna ainda mais necessário em nosso próprio momento histórico. $\mathrm{O}$ que, para Blake, era um futuro que prometia libertá-lo de seu presente desapareceu no tecido de nossa própria herança política e cultural. Olhamos de volta para Blake através de um grande espaço vazio, na medida em que vivemos uma realidade que existe porque as revoluções proletárias do século xIx não tiveram êxito. Somos mais os herdeiros da realidade restritiva de Blake do que do futuro imaginado por ele. Dito de outro modo, sua poesia ainda nos fala porque ainda não nos libertamos para ouvi-la.

John Brenkman éprofessor deliteratura norte-americana eliteratura comparada na The City University of New York - CunY, onde dirige o Seminário EUA-Europa no Baruch College. Foi editor-fundador da revista Social Text. É autor de Culture and domination (Cornell up) e Straight male modern: a cultural critique of psychoanalysis (Routledge), entre outros títulos. Contribuiu com o ensaio "Innovation: notes on nihilism and the aesthetics of the novel" para o volume 2 de The novel. Themes and forms, obra coletiva editada por Franco Moretti (Princeton UP), sendo ainda autor de mais de cinquenta ensaios e artigos. Colaborou para o blog http://www.greatissuesforum.org/ (Seminar@The Forum). 